\title{
The experimental investigation of pipes system array inside the pressurized cylindrical container in various orientations
}

\author{
Hayam Majeed Esmaeel ${ }^{1 *}$, Ammar A. Badai ${ }^{1}$, Majid H. Majeed ${ }^{1}$ \\ 1. The Baghdad engineering technical college/ The Midland Technical University/ Baghdad- \\ Iraq. \\ *Corresponding Email: hiyammajeed87@gmail.com
}

\begin{abstract}
The experimental investigation of natural convection analysis in pressurized containers has been successfully addressed fusing four identical circular rectangle pipes. The pressurized tank of $0.3 \mathrm{~m}$ diameter and $0.45 \mathrm{~m}$ height within $0.43 \mathrm{~m}$ height and $0.025 \mathrm{~m}$ side length interior square pipes are used to obtain the present investigation. Various parameters are used such as gauge pressure (0.5-1 bar), pipes Ra configurations and enclosure orientations. The results are Nusselt number for cold and hot sides. Both sides has reverse response, the parametric analysis shows the ordinary behavior according to gravity and pressure forces interaction. The optimum conditions is observed when horizontal enclosure of top pipe in one bar is applied where the heat transfer improvement is $24 \%$ approximately.
\end{abstract}

Keywords: Free convection, enclosure, rectangular pipe, $\mathrm{Nu}$,

\section{Introduction}

Free convection heat transfer is vital in a wide range of industrial and domestic applications. The most important topic for manufacturing proposal, process, inquiry, and development is the analysis of heat transfer for cooling or heating purposes. The growth of heat transfer by employing exceptional techniques improves higher mean excellences, resulting in more efficient power conservation and administration (Sheikholeslami et $\boldsymbol{a l}$. , 2015). Rising the heat transfer coefficient by means of physical characteristics configuration and by area by geometrical and design configurations limits the rate of heat transfer. Because to boundary layer interactions between the cold and hot surfaces, the complexity of free convection grows in an irregular pattern, forming an unusual free stream structure and an unusual boundary layer, similar to forced convection (Barakos, Mitsoulis and Assimacopoulos, 1994). The behavior of free convection is explained by the density difference in gravity 
direction caused by buoyancy (Brodkey and Hershey, 1998; Chamkha and Ismael, 2013) A heated surface in a circular container is an active example of free convective heat transfer. Within a hot surface, the momentum rate of natural convection is minimal (no-slip condition). By the action of displacement and heat transmission among fluid particles, the momentum rate rose significantly away from the heated domain inside the free stream. Understanding the active free convection criterion helps with the design, operation, and thermal analysis of a variety of industrial and urban heating and cooling systems (Theodore, 2011) .

Previous research looked at natural convection heat transfer inside an enclosure under various operating parameters and geometries such as: Kitamura et al.( 1999), , investigated the heat transfer free convection by displaying the free stream configuration in the region of the external surface of a cylindrical pipe and calculating the external surface temperature allocation, the natural convection behavior. According to the authors, 3D free stream separation occurs first at the pipe's uneven limits and then transforms to the turbulent non-fully developed scenario. The researchers also discovered that the confined $\mathrm{Nu}$ increases significantly in section of the non-developed region and turbulent stream, despite the fact that these sections are used on an undersized division of the pipe's exterior surface. Empirical expressions for the man $\mathrm{Nu}$ were obtained as prevails in the following:

$$
N u=0.6 R a_{D}{ }^{* 0.2}, \quad \text { at } 3 \times 10^{8}<\mathrm{Ra}<2.5 \times 10^{10}
$$

Habeeb, 2010 investigated The impact of a hot square pipe placed on a cooled elliptical pressurized enclosure of a laminar free convection system numerically. For two positions of the main axis of the elliptical pressurized tank, horizontal and vertical), this statement was solved using the PDE Algorithm. Speed vectors, streamlines, heat lines, and $\mathrm{Nu}$ were the most common outcomes. The results revealed that increasing the amplitude of the enclosure's main axis increased the average $\mathrm{Nu}$ and decreased the momentum strength for the whole $\mathrm{Nu}$. However, when $\mathrm{Ra}$ increased, the results changed dramatically. Salman and Shamikh, in (2012) investigated numerically of free convection behavior in a closed pressurized annulus region is formed by heated square pipe in a larger constant temperature surface of cooled cylinder pipe. The numerical simulation was carried out by using profitable 
CFD package (FLUENT 6.3). The average $\mathrm{Nu}$ from the investigational results was compared with that resulted from the CFD package. The stream lines and heat lines characteristics for various operating and geometric conditions were involved from side to side stream lines and isotherms contours that obtained from the CFD package. The Aspect ratio range from 0.2 to 0.5 was also used. The results prevailed that the $\mathrm{Nu}$ is affected directly by aspect ratio, the increasing of aspect ratio leads to $\mathrm{Nu}$ increasing. Also the consequence prevailed that as $\mathrm{Ra}$ increasing leads to $\mathrm{Nu}$ increasing with significant effect. Altaee et al., (2017), studied the numerical analysis of a heated triangular body inside a cold rectangular chamber filled with air. The influence of triangular body tilt and Ra on the numerical study was examined using the ANSYS 16 CFD software. They were able to create streamline counters with varied inclination degrees and Ra. Pandey et al., in (2019) investigated numerically and empirically, a full description of natural convection in enclosures with and without interior bodies. Square, circular, and elliptical cylinders are frequently used as internal bodies. The impacts of many factors on the flow regime and thermal fields, such as internal body location, Rayleigh number, aspect ratio, inclination angle, and number of internal bodies, have been thoroughly explored. The scope of present investigation is to develop parametric trend of $\mathrm{Ra}$, pressure and enclosure orientation on the heat transfer performance.

\section{The experimental setup}

The investigation of natural convection inside a pressurized annular tank with four rectangular pipes is part of the experimental investigation. The goal of this experiment is to see how heat fluxes, the number of heated rectangular pipes, the orientations of the pressured vessel, and the pressure affect the heat transfer coefficient and Nusselt number. For this study, precise measurement instruments were utilized to collect data, and a high-quality statistical technique was applied to discover the empirical connection. Figure 1 shows the experimental set up. The pressurized tank, pipes with inner heaters, ambient air tubes, air compressor, variac, voltmeter, ammeter, pressure gauge, and data-logger are the major components of the experimental rig. The current work's rig configuration is used to test the various parameters. The pressurized vessel is a cylindrical container with a thick iron wall and dimensions of $0.45 \mathrm{~m}$ in height and $0.3 \mathrm{~m}$ in diameter. Four rectangular holes at the top of the vessel., the hot four square pipes are placed in fixed distane. The $0.11 \mathrm{~m}$ 
difference in distance between the center of each pipe. The two pipes include heaters with a height of $0.4 \mathrm{~m}$ and a maximum power of $1000 \mathrm{~W}$ that are fixed parallel to the tube to provide a consistent heat flow. The tube's power may be varied using a manual voltage regulator, whereas the other pipes are merely filled with ambient air. The pipes have a height of $0.43 \mathrm{~m}$ and a side length of $0.25 \mathrm{~m}$. During the experiment, the pressure vessel is kept sealed and insulated.

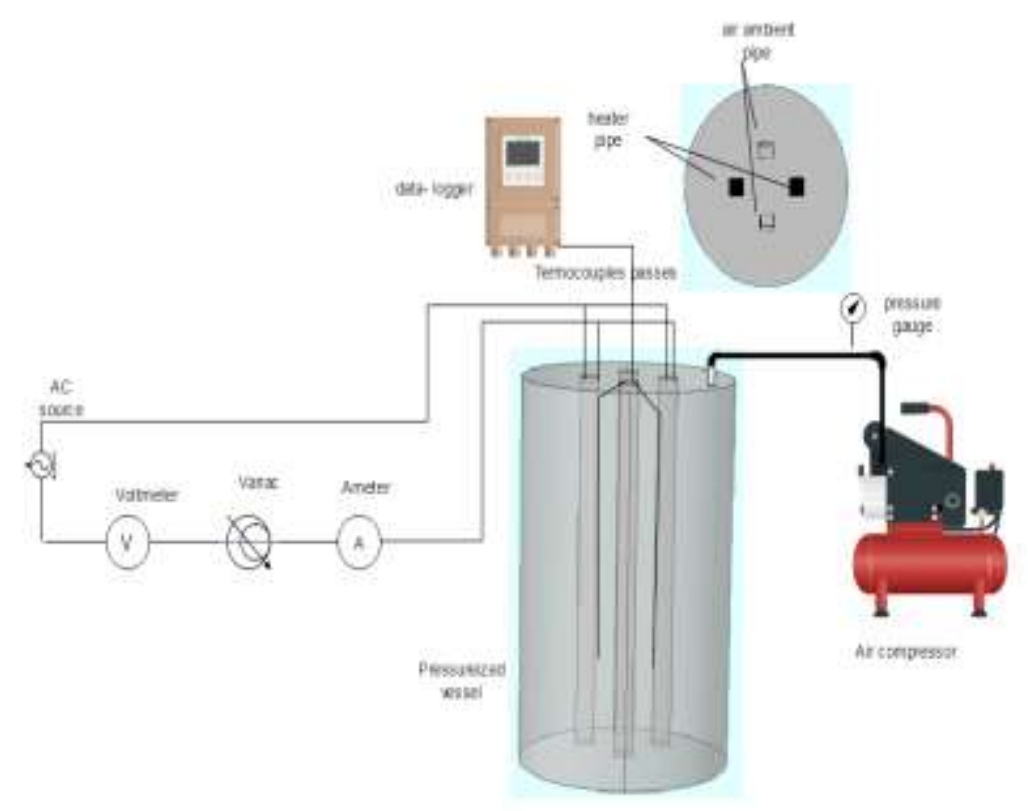

Figure 1: Rig setup of experimental work.

The following components can be used to summarize the experimental procedure: The compressor is turned on until the pressure within the pressurized vessel reaches the specified level. The heaters are turned on, the voltage regulator adjusts the voltage to the desired level, and the temperature is measured at steady state, when the temperature values are steady constant. The procedure can be repeated for different voltages (10-110 V) at gauge pressures (0.5-1 bar). To accomplish free convective heat transfer, the aforementioned pressures and voltages can be utilized for one heater instead of two heaters, and three pipes will be filled with ambient air. For the given characteristics, the pressurized vessel can be used both vertically and horizontally.

\section{The data collection}

The data was collected as temperature distribution inside circular enclosure. The constant surface heat flux can be calculated from the following expression: 


$$
q=\frac{V \times I-Q_{\mathrm{rad}}}{A}
$$

Where: $\mathrm{V}$ is electrical potential, I is electric current, $\mathrm{A}$ is outer surface area of inner cylinder, and $Q_{\text {rad }}$ is the heat transfer by radiation between circular cylinder and triangular cylinder which can be calculated as follows:

$$
Q_{\text {rad }}=\frac{\sigma\left[\left(T_{i}+273\right)^{4}-\left(T_{o}+273\right)^{4}\right]}{\left[\frac{1-E_{1}}{A E_{1}}+\frac{1}{A F_{12}}+\frac{1-E_{2}}{A E_{2}}\right]}
$$

where

$T_{i n}$ is the average hot temperature of inner square cylinder wall

$T_{\text {out }}$ is the average cold temperature of outer enclosure

$\sigma=$ Stefan Beltzman constant $=5.66 \times 10^{-8} \mathrm{~W} / \mathrm{m}^{2}{ }^{\circ} \mathrm{K}^{4}$

$E 1=E 2=$ emissivity of the iron inner and outer surfaces $=0.21$.

$F_{1-2}=$ Radiation View factors $\approx 0.1$

The heat transfer coefficient can be calculated from the following expression:

$h=\frac{q}{T_{\text {in }}-T_{\infty}}$

where $\mathrm{T}_{\infty}$ is averagehot air temperature inside the enclosure.

The Nusselt number can be calculated from follows:

$N u=\frac{h L}{\kappa}$

The Rayleigh number can be calculated from the following :

$$
R a=\frac{g \beta\left(T_{\text {in }}-T_{\text {out }}\right) L^{3} p^{2}}{\mu^{2}} \operatorname{Pr}
$$




$$
\text { And } \quad \mathrm{D}=M w t \frac{P}{R T}
$$

The logarithmic mean Nusselt number data can be fitted as linear relation with logarithmic Rayleigh number by using Ms-Excel trend-line to obtain the empirical correlation for each as expressed as follows:

$$
N u=c R a^{n}
$$

Where $\mathrm{c}$ and $\mathrm{n}$ are empirical constants which can be change by changing the enclosure

All the air physical properties $\rho, \mu, v$, and $\kappa$ were evaluated at the average mean film temperature $\left(T_{f}\right)$.

$$
T_{f}=\frac{T_{h}+T_{\infty}}{2}
$$

\section{The results and discussion}

\section{The effect of pressure on Nusselt number}

Figures 2 and 3 show $\ln \mathrm{Nu}$ vs. In Ra for various pressures for both cold and hot circular rectangle pipes, where vertical orientations are applied with two heated pipes. The general behavior for cold pipes is reversible to hot pipes, for cold pipes higher pressure means higher Nusselt and vice versa for hot pipes. The increasing of pressure reduces the free convection action for hot particles which means the hot fluid has resistance forces against gravity action (density difference). The cold pipes has higher mixing intensity with hot particles more than mixing intensity of hot side with cold fluid particles. 


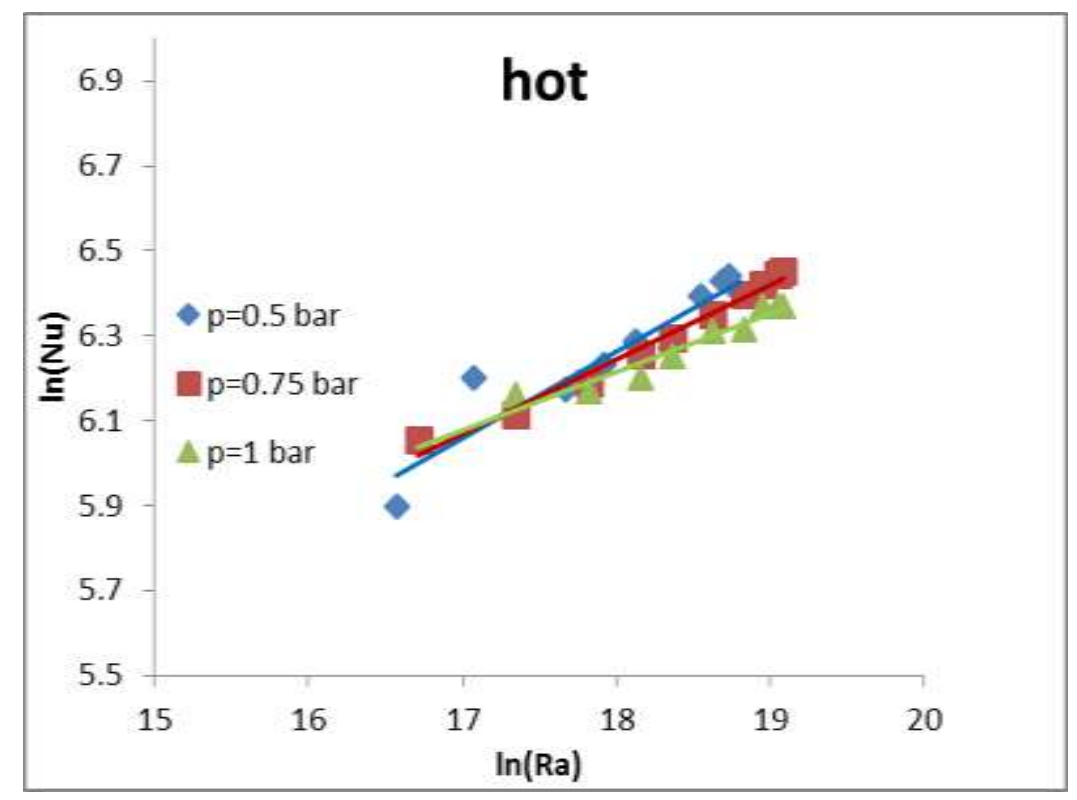

Figure 2: ln Nu vs. ln Ra for Various Gauge gauge pressures and hot pipes when vertical two hot pipes are used.

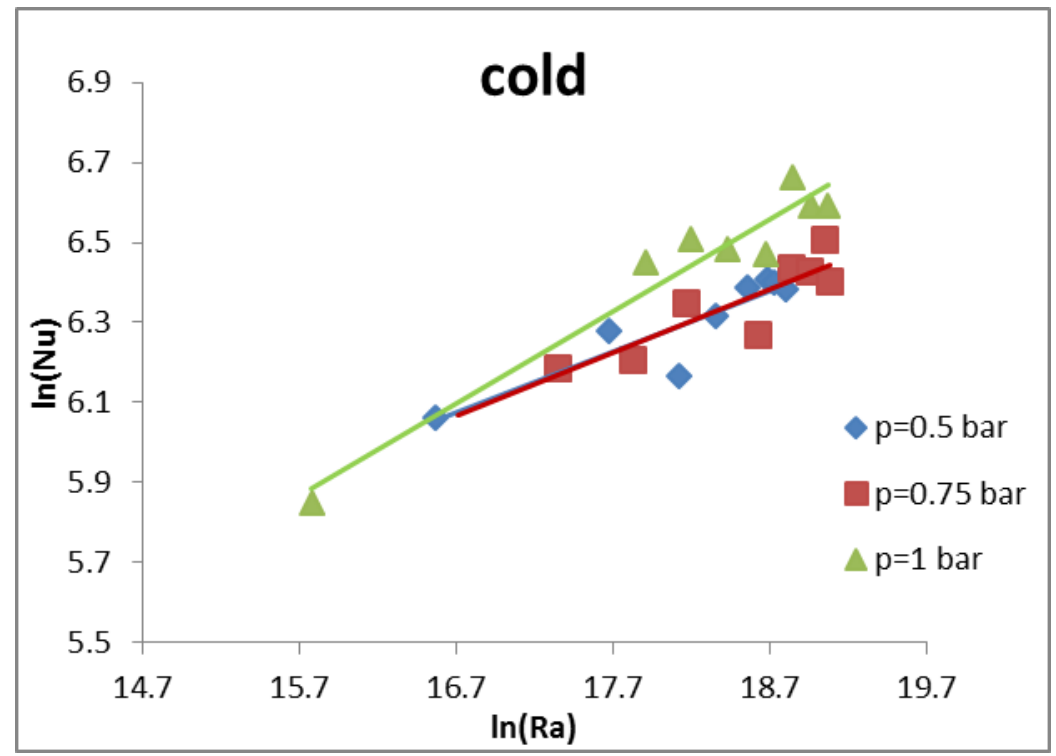

Figure 3: ln Nu vs. ln Ra for Various Pressures and cold pipes when vertical two hot pipes are used.

\section{The effect of enclosure orientation on Nusselt number}

Figures 4 and 5 show $\ln \mathrm{Nu}$ vs. In Ra for various pressures for both cold and hot circular rectangle pipes, where horizontal orientations are applied with two heated pipes. The same general behavior is observed in vertical case. The horizontal orientation has Nusselt number range higher than the vertical case, where the 
increasing amount is about $5 \%$. The mixing action a long circular rectangle pipes has sufficient affected on the larger fluid volume in horizontal case for whole operating pressure.

Figure 4: ln Nu vs. In Ra for Various Pressures and hot pipes when Horizontal two hot pipes are used.

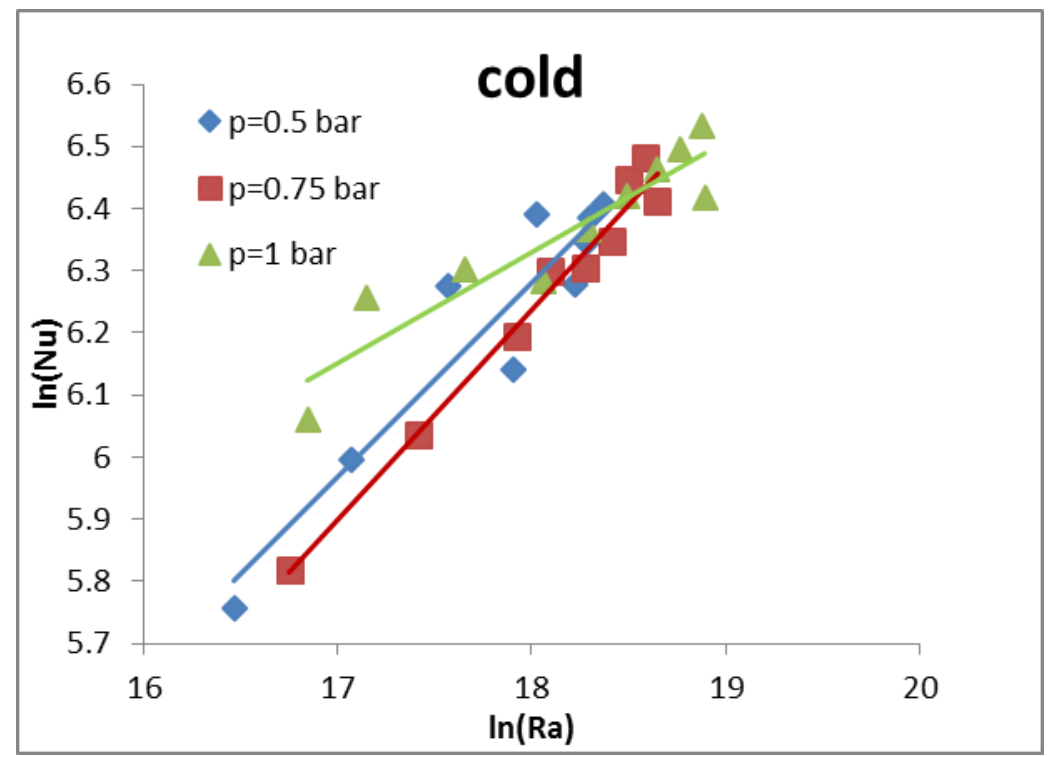

Figure 5: ln Nu vs. In Ra for Various Pressures and cold pipes when Horizontal two cold pipes are used.

\section{The effect of pipes configuration on Nusselt number}

Figures 6 and 7 show $\ln \mathrm{Nu}$ vs. In Ra for various pressures for both cold and hot circular rectangle pipes, where vertical orientations are applied with one heated pipe. The general behavior is different from the two pipes case. For hot sides the increasing of pressure increases the hot $\mathrm{Nu}$ and the non- ordinary behavior is observed in cold side $\mathrm{Nu}$. The results indicates $9.5 \%$ heat transfer enhancement while cold $\mathrm{Nu}$ decreases by $17 \%$ because the heat transfer rate will be divided for the whole three pipes where the hot pipe dealt with the higher cold fluid volume. 


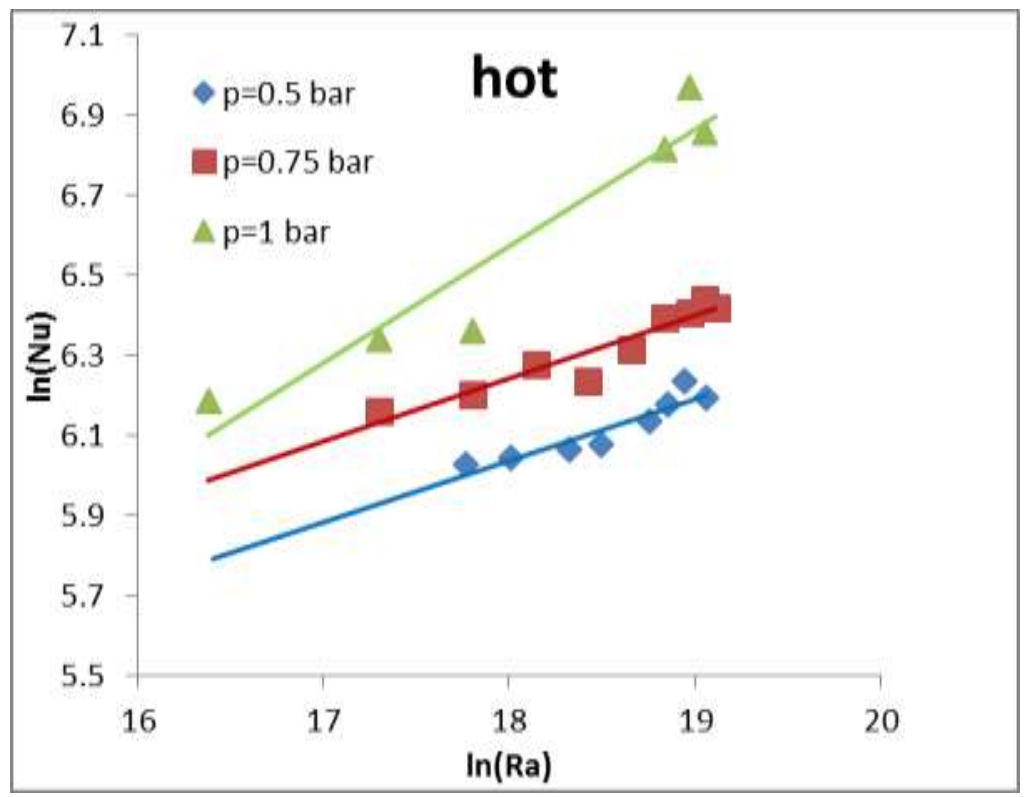

Figure 6: ln Nu vs. ln Ra for Various Pressures and hot pipe when vertical one hot pipe is used.

Figures 8 - 11 show $\ln \mathrm{Nu}$ vs. In Ra for various pressures for both cold and hot circular rectangle pipes, where horizontal orientations are applied with one heated pipe from top or bottom. The both cases has non- ordinary behavior for both sides (hot and cold $\mathrm{Nu}$ ) with Ra. The position of hot pipe (top nd bottom) controls the heat transfer characteristics in present system. For the top pipe, the maximum heat transfer mixing is observed on hot region at high pressure value where the maximum displacement between cod and hot fluid particles is obtained. The optimum heat transfer enhancement is about $24 \%$ in hot side, top one horizontal pipe.

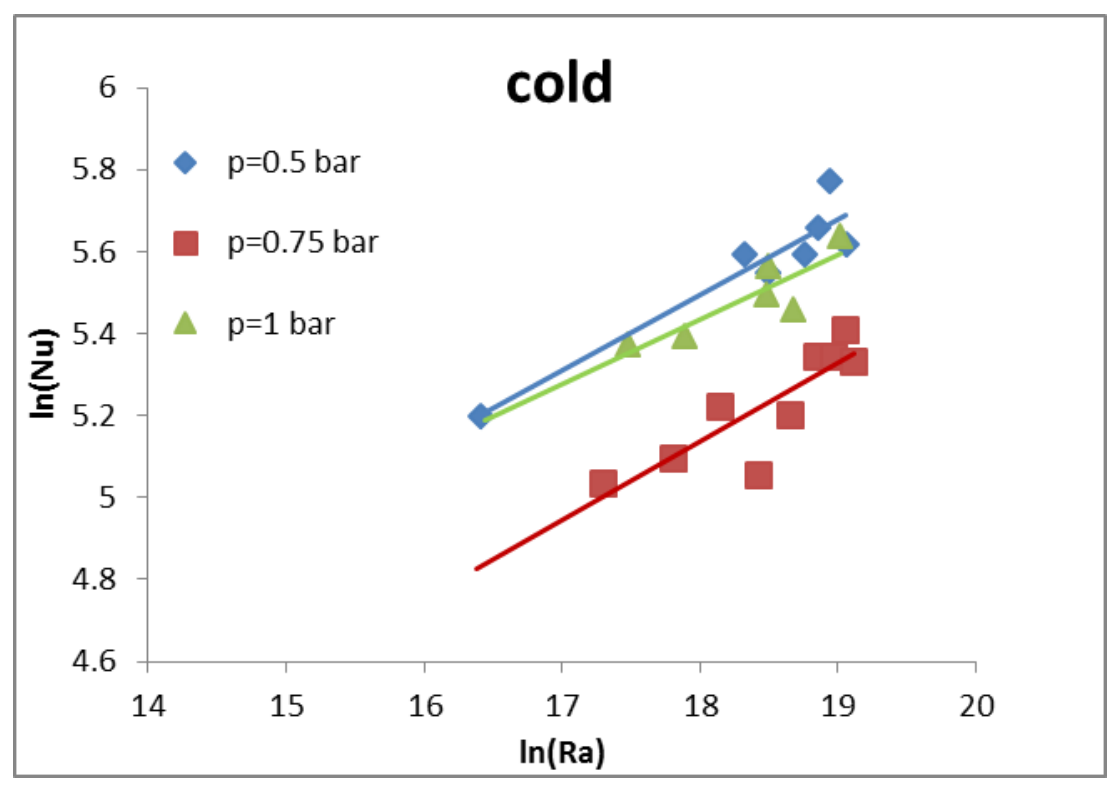

Figure 7: ln Nu vs. ln Ra for Various Pressures and cold pipes when vertical one hot pipe is used. 


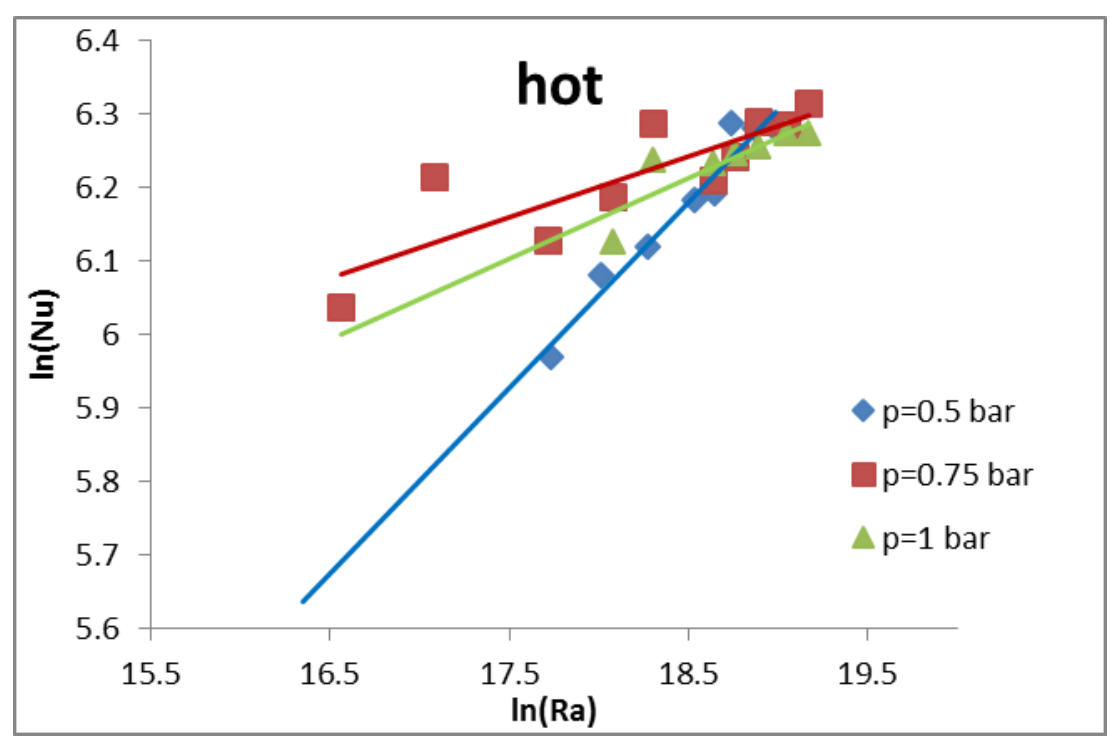

Figure 8: ln Nu vs. ln Ra for Various Pressures and hot pipe when horizontal bottom one hot pipe is used.

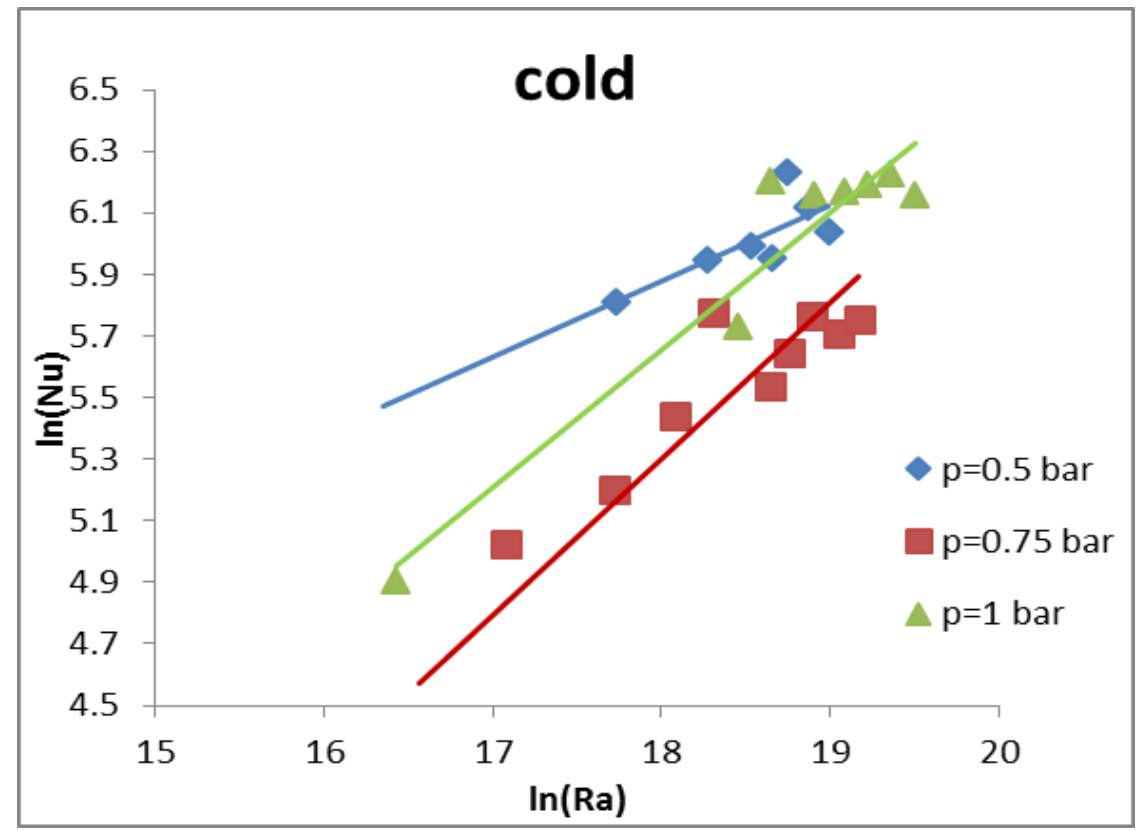

Figure 9: ln Nu vs. In Ra for Various Pressures and cold pipes when horizontal bottom one hot pipe is used. 


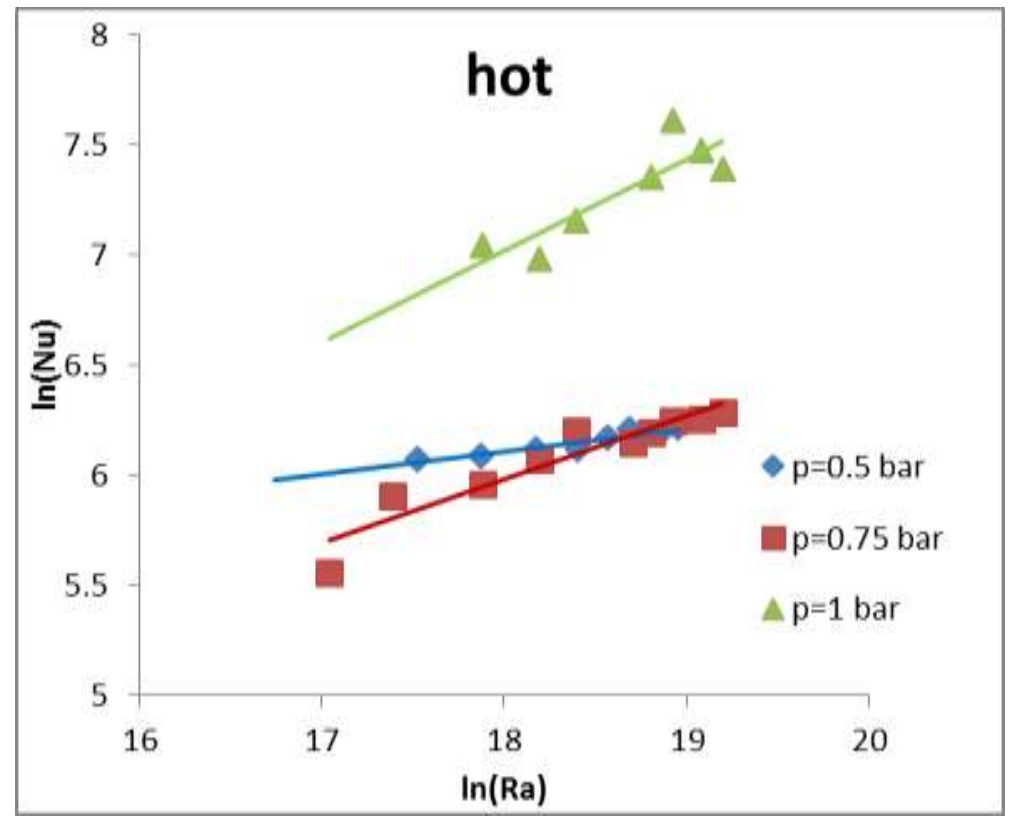

Figure 10: ln Nu vs. ln Ra for Various Pressures and hot pipe when horizontal top one hot pipe is used.

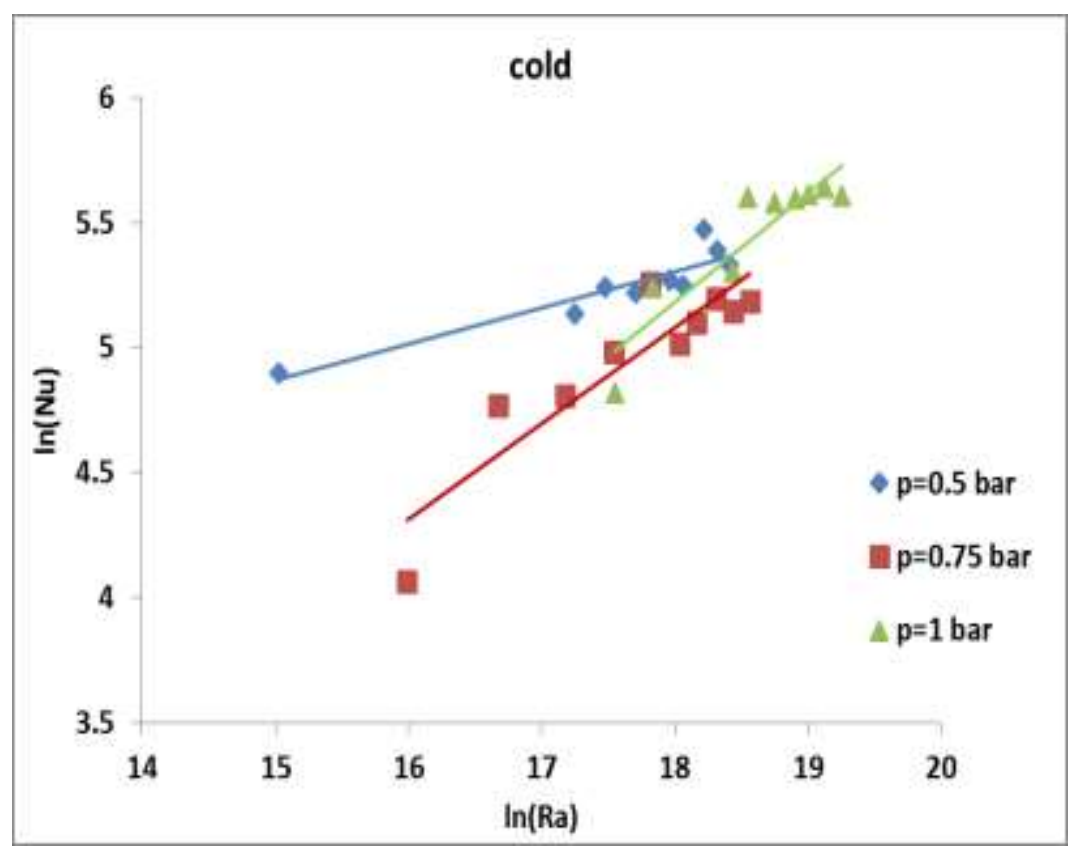

Figure 11: ln $\mathrm{Nu}$ vs. In Ra for Various Pressures and cold pipes when horizontal top one hot pipe is used.

\section{Conclusions}

The experimental investigation of pressurized tank free convection for various operation conditions has been established successfully. The results indicates the effect of pressure, enclosure orientation and pipes configuration on cold and hot Nusselt numbers. The increasing of cold $\mathrm{Nu}$ is mean the decreasing in hot $\mathrm{Nu}$ generally. The 
pressure has direct effect on Nusselt number. The horizontal orientation has $5 \%$ heat transfer enhancement from the vertical case for two hot pipes configuration. The heat transfer improvement of $9.5 \%$ is also observed when the one hot pipe configuration is used. In vertical orientation. The optimum operating condition is observed when the top one hot horizontal pipe configuration is used, the enhancement is $24 \%$ approximately.

\section{References}

Altaee, A. H., Farooq Hassan Ali and Mahdi, Q. A. (2017) 'Natural Convection Inside Square Enclosure Containing Equilateral Triangle with Different Orientations', Journal of University of Babylon, 25(4), pp. 1194-1205.

Barakos, G., Mitsoulis, E. and Assimacopoulos, D. (1994) 'Natural convection flow in a square cavity revisited: Laminar and turbulent models with wall functions', International Journal for Numerical Methods in Fluids, 18(7), pp. 695-719. doi: 10.1002/fld.1650180705.

Brodkey, R. S. and Hershey, H. C. (1998) Transport Phenomena: A Unified Approach. Singapore: McGraw-Hill Series. doi: 10.1080/07373938808916409.

Chamkha, A. J. and Ismael, M. A. (2013) 'International Journal of Thermal Sciences Conjugate heat transfer in a porous cavity fi lled with nano fl uids and heated by a triangular thick wall', International Journal of Thermal Sciences. Elsevier Masson SAS, 67, pp. 135-151. doi: 10.1016/j.ijthermalsci.2012.12.002.

Habeeb, S. J. (2010) 'Investigation of heat transfer phenomena and natural flow behavior around a heated square cylinder placed in a cooled elliptical enclosure', Mathematics, pp. 1-18.

Kitamura, K., Kami-iwa, F. and Misumi, T. (1999) 'Heat transfer and fluid flow of natural convection around large horizontal cylinders', International Journal of Heat and Mass Transfer, 42, pp. 4093-4106.

Pandey, S., Park, Y. G. and Ha, M. Y. (2019) 'An exhaustive review of studies on natural convection in enclosures with and without internal bodies of various shapes', International Journal of Heat and Mass Transfer. Elsevier Ltd, 138, pp. 762-795. doi: 10.1016/j.ijheatmasstransfer.2019.04.097.

Salman, L. A. and Shamikh, A. J. J. (2012) 'Experimental and theoritical study of natural convection heat transfer of heated square cylinder placed inside a cooled circular enclosure filled with air', The Iraqi Journal For Mechanical And Material Engineering, 12(3), pp. 564-581.

Sheikholeslami, M. et al. (2015) 'Thermal management of double-pipe air to water heat exchanger', Energy and Buildings. Elsevier B.V., 88, pp. 361-366. doi: 10.1016/j.enbuild.2014.11.076.

Theodore, L. (2011) Heat Transfer Applications for the Practicing Engineer. New Jersey: JohnWiley \& Sons, Inc. doi: 10.1002/9781118827123. 